\section{Comprehensive Care}

SIR,-Dr. D. H. Judson in his letter (15 June, p. 701) has put his finger on the major difficulty in the use of attached nursing personnel in general practice.

There is no doubt that nurse training is no more appropriate for today's general practice than is the training received by the average doctor. The difficulty in providing a satisfying job for her is even more understandable when one reads published accounts of the nurse's work consisting in minor technical procedures such as prophylactic injections, therapeutic injections, dressings, venepunctures, ear syringing, and blood pressure recording. The work of a family nurse should cover the whole range of general practice. She needs to remain, as the doctor does, a generalist, and the distinction to be made between their work is the level at which it is carried out. There are, thus, elements of diagnosis and therapy, of health education and preventive medicine, of social and psychiatric medicine, within her range of competence.

The needs of general practice will only be met when we have attachment ratios of one nurse to one doctor. A total of 25,000 family doctors working with 25,000 family nurses makes more sense than the 50,000 family doctors envisaged by the Royal Commission on Medical Education. Traditional nurse training is aimed primarily at hospital employment, and the attitudes of doctor and nurse are determined by this. I have already described ${ }^{1}$ one method by which the family nurses' training could be carried out if based upon the pattern of the two-year, junior college, nurse training schemes in the U.S.A. Colleges of further education in this country would provide the right pedagogic anproach to this, supervised by the Royal College of Nursing. The courses would contain inservice training in both hospital and general practice, and could be integrated with parts of the vocational training programme for general practice as suggested by the report from the Institute for Social Research. ${ }^{3}$

I believe that it is now widely recognized that a fundamentally new approach is necessary towards the staffing of general practice, and that it is necessary to have training that is appropriate to the job and not modified from other jobs. The Royal College of Nursing and general practitioners have a great opportunity here which they should seize with both hands.-I am, etc.,

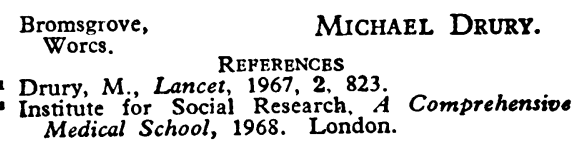

\section{L.S.D. and Chromosomes}

SIR,-Y Your leading article on the genetic aspects of L.S.D. (29 June, p. 778) gives a well-balanced appraisal of the evidence on the subject. But your opening comment is odd: ". . . because the drug is used in psychiatric medicine and as a hallucinogen for 'kicks' it needs thorough study." Surely any drug, except perhaps one immediately life-saving, should be subject to thorough scrutiny lest it does genetic damage; whether it is used in psychiatry or general medicine is hardly distinctive. Equally any synthetic taken by the public should be quite as care- fully screened. A commercial food additive could do much more damage than a substance used for "kicks" by relatively few.

Perhaps your comment really conceals within it another problem. Responsible people, for other and quite sufficient reasons, want to discourage the young-students and the like-from taking " trips" illicitly. There has been a suggestion that L.S.D. might on occasions be genetically harmful, and if that could be demonstrated promptly and conclusively it would act as a deterrent to potential users. But it would be a pity if this entirely proper intention was needlessly to impede clinical studies of L.S.D. as an adjuvant to the treatment of neuroses and other psychiatric conditions. The results of psychotherapy of any kind are still not very good, and there is a real need to study every possible method to the full. You are right that concern should be shown and further studies on genetic risks be undertaken. But since the practical implications of these

\section{Skin Preparation and Intramuscular Injections}

SIR,-It is not often that a dangerous philosophy based on inadequate evidence has the opportunity of being restated in a widely read and authoritative journal such as the British Medical fournal. This has happened in the letter by Dr. T. C. Dann (11 May, p. 367) in which he reiterates a view he pre-

of death on the roads simply because he has driven for 1,078 weeks and has never been involved in a fatal road accident. If Dr. Dann elected to keep his "discovery" a secret no one, except a few unfortunate patients, would have cause to complain, but when he recommends that this practice should
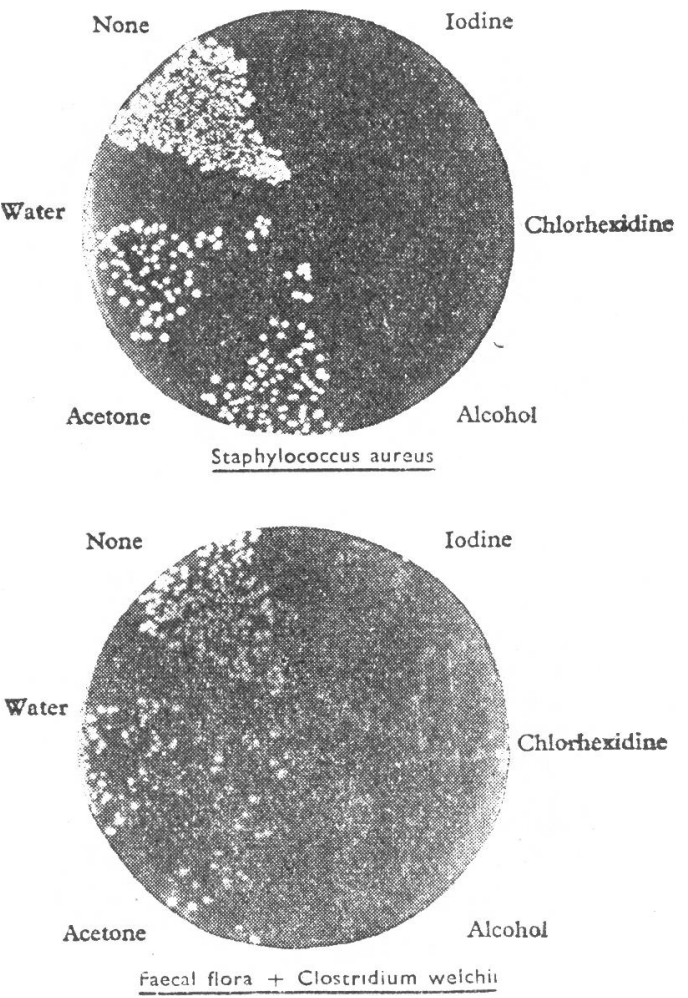

Showing the effect of mechanical removal, which is sligh after 5 -second treatment, and chemical disinfection, which is highly effective. $\mathrm{Cl}$. welchii was non-sporing.

viously put forward'-namely, that routine skin preparation before injection is an unnecessary procedure. This surprising recommendation seems to be based on the author's good luck in that he observed no infections after giving 1,078 injections (probably more by now) without any skin preparation. The reasoning which emerges from this experience is not unlike a person denying the reality be adopted universally then we must reject his recommendations emphatically.

Perhaps the following experiment sammarized in the Table and Figure below will convince your readers, and, hopefully, Dr. Dann, that a five-second preinjection skin preparation will effectively remove and destroy the transient flora of vegetative organisms. 
Efficiency of Removal of Transient Skin Flora by a Five-second Skin Treatment

\begin{tabular}{|c|c|c|c|}
\hline \multirow{2}{*}{$\begin{array}{l}\text { Skin Treated } \\
\text { with }\end{array}$} & \multicolumn{3}{|c|}{$\begin{array}{c}\text { Skin Contaminated with } \\
\text { Suspension Containing } 10^{6} / \mathrm{ml} \text {. }\end{array}$} \\
\hline & $\begin{array}{l}\text { Staph. } \\
\text { aureus } \\
\text { (10\% } \\
\text { Serum) }\end{array}$ & $\begin{array}{c}E \\
c o l i \\
(10 \% \\
\text { Faeces) }\end{array}$ & $\begin{array}{c}\text { Cl. } \\
\text { welchii } \\
\text { (10\% } \\
\text { Faeces) }\end{array}$ \\
\hline $\begin{array}{l}\text { Nothing-control } \\
\text { Sterile water } \\
\text { Accotone } \\
\text { Alcohol }(80 \% \text { v } / \mathrm{v}) \\
0.5 \% \text { chlorhexidine } \\
\text { in alcohol } \\
\text { Tinct. iodine B.P. }\end{array}$ & $\begin{array}{c}++ \\
++ \\
++ \\
+\end{array}$ & $\begin{array}{c}++ \\
++ \\
++ \\
+\end{array}$ & $\begin{array}{c}+++ \\
++ \\
+ \\
=\end{array}$ \\
\hline
\end{tabular}

Skin sampled with moist swabs, plated and incubated for 48 hours at $37^{\circ} \mathrm{C}$.

+++ signifies uncountable; $++10-100$ colonies;

$+<10$ colonies; - no growth.

These results, which any microbiologist can confirm in a few days, clearly demonstrate that it is possible to remove vegetative contaminants from the skin under worst-case conditions-that is, after a five-second swabbing. Dr. Dann is being less than frank when he implies that he has shown that alcoholic skin disinfectants fail to achieve this when used in practice. His paper contains no bacteriological evidence on the efficiency or otherwise of the commonly used skin disinfectants.-We are, etc.,

SYDNEY D. RUBBO.

JOAN F. GARDNER.

Department of Microbiology,
University of Melbourne,

Victoria, Australia.

RBFERENCES

' Dann, T. C., Practitioner, 1966, 196, 546.

\section{Initiation of Labour}

SIR,-I should like to put forward a suggestion which goes towards correlating existing theories and observations as to the mechanism of initiation of labour. The withdrawal of progesterone is known to precipitate labour, ${ }^{1}$ and it has been suggested that sudden involution of the corpus luteum of pregnancy might cause a sudden fall in the blood progesterone level, but Short and Eton $^{2}$ were unable to demonstrate any correlation between the blood progesterone levels and the onset of labour. Oxytocin has little action on the non-pregnant uterus, and only acts on uterine muscle that has been subjected to the action of progesterone. As with progesterone levels, there is no evidence of any abrupt change in blood oxytocin levels immediately prior to the onset of labour. Work by Riad and Scandrett ${ }^{3}$ on the levels of oxytocinase similarly failed to reveal any marked change prior to the onset of labour.

The optimum $p \mathrm{H}$ for the activity of oxytocinase is $7.3,{ }^{4}$ and interestingly enough the $\mathrm{pH}$ of the amniotic fluid is of this magnitude for the greater part of pregnancy, ${ }^{s}$ only falling to a level of $p H 7.0$ or less at 39 weeks' gestation. ${ }^{6}$ At a level of $p \mathrm{H} 7.0$ or less the activity of oxytocinase is markedly reduced, and therefore the possibility exists that although there is no marked change in the level of oxytocinase in the amniotic fluid as term is approached, there is a reduction in the biological activity of this enzyme due to the fall in $p \mathrm{H}$. The oxytocinase in the amniotic fluid may be presumed to inactivate the oxytocin that reaches the amniotic fluid and thus prevent it from ciffusing through the decidua to reach the myometrium. The amniotic acidosis occurring as term is approached is brought about by a foetal metabolic acidosis caused by increased activity on the part of the foetus.' This amniotic acidosis, by causing a reduction in the activity of oxytocinase, may result in an increase in the amount of oxytocin in the amniotic fluid, and this in turn might result in an increased diffusion of oxytocin across the decidua to the myometrium, thus giving rise to contraction of the uterine muscle.

It is therefore suggested that increasing foetal activity as term is approached may result in acidotic inhibition of oxytocinase in the amniotic fluid with a consequent rise in the amount of oxytocin in the fluid. Because of this rise diffusion of oxytocin across the decidua may occur and myometrial stimulation follow. The concept of a $\mathrm{pH}$ change in the amniotic fluid being responsible for the onset of labour would not be incompatible with the observation of Bengtsson and Csapo, that a solution of hypertonic saline administered into the amniotic fluid can produce termination of pregnancy. The diffusion of oxytocin across the decidua might not be in uniform amounts over the whole of its surface, and this would explain the existence of "functional asymmetry" of the uterus observed by Csapo." The fact that women with diabetes insipidus go into labour normally has been advanced as an argument against oxytocin having an important part to play in the onset of labour. However, polypeptides other than oxytocin produced at sites elsewhere than the posterior pituitary might be of importance in these cases, and these "alternatives" to oxytocin may well be destroyed by oxytocinase in the same manner. The fact that labour not infrequently ensues after the intrauterine death of a foetus does not invalidate the hypothesis, as in this instance there will also be a $p H$ change.-I am, etc.,

\section{West London Hospital,}

\section{A. Boulton Hewitt}

London W.6.

\section{REFERENCBS}

Reynolds, S. R. M., Physiology of the Uterus, 1949, 2nd ed. New York.

Short, R. V., and Eton, B., F. Endocr., 1959, 18, 418.

(Lond.), $1962,193,372$.

Tupyd.), 1962, 193, 372 . Muscles in Polypeptides Which Affect Smooth Schachter, 1960 p. 49. Oxford.

Siöstedt, S., Rooth, G., and Caligara, F., Amer. I. Obstet. Gynec., G., and Cali

Hewitt, A. B., 1962, unpublished observation

Rooth, G., Siöstedt, S., and Caligara, F., Amer. f. Obstet. Gynec., 1961, 81, 4

Bengtsson, L. P., and Csapo, A. I., Amer. F.

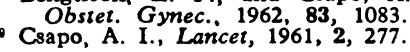

\section{Operations for Duodenal Ulcer}

SIR,-Your leading article and the articles by Professor J. C. Goligher and others (29 June, pp. 776, 781, and 787) indicate that there is little difference in the late results of different operations for duodenal ulcer. Surely this makes a strong case for conservative operations. Quite apart from the lower immediate mortality, a successful vagotomy and pyloroplasty leaves the stomach in a near-normal condition, whereas even the most successful gastrectomy leaves the patient with only a part of his stomach.

Indeed, the comparison of conservative and excisional operations on the stomach is a little unfair. It is like comparing the operations of lumbar sympathectomy and amputation in the treatment of vascular insufficiency of the foot. Sympathectomy is a relatively minor operation and it may be successful, although as a certain cure for a disabled foot it is obviously not as reliable as amputation, but the smaller operation will save a certain number of patients from being permanently crippled. A failed conservative operation on the stomach can be followed by an excisional operation in the same way as amputation of the foot may be required after a failed sympathectomy. Conservative and excisional operation on the stomach should be regarded more as allies than rivals, complementary rather than alternative. An important point which follows from this is that " the conservative operation of vagotomy and pyloroplasty can be recommended to a patient with a duodenal ulcer early in his illness. On the other hand, a gastrectomy, because of its sequelae, can be done only after the patient has suffered a long timeafter he has 'earned' his gastrectomy."'

Perhaps the strongest argument in favour of conservative surgery for duodenal ulcer to be found in the articles by Professor Goligher and others is their statement that since 1962, the trial being over, they are employing vagotomy and pyloroplasty in $90 \%$ and vagotomy and gastroenterostomy in the remaining $10 \%$ of their cases. - I am, etc.,

London W.1.

Grorge Qvist.

1 Dreyer, B. J. v. R., Lancet, 1963, 2, 251.

\section{Tumours of the Oesophagus}

SIR,-Your leader writer (29 June, p. 779) pays scant attention to the Japanese contribution to this field. There, experience is based on a high local incidence of carcinoma of the oesophagus which is comparable to that of bronchial neoplasm in this country.

Nakayama et al. ${ }^{1}$ have published a new approach to curative treatment, involving preoperative irradiation and a three-stage operation with extrathoracic restoration of the gullet. Surgical clearance of the growth is not limited by the need for primary restoration of the gullet. The dangers associated with intrathoracic leak at the anastomosis are removed. A prosthetic gullet provides initial palliation, and allows reconstructive surgery to be reserved for those patients who progress well. The above authors state that 301 cases of carcinoma of the oesophagus and gastric cardia have been found in the surgical literature as 5-year survivors following radical operation, and that 120 are personal to Nakayama. Such an experienced authority advocating a new combined approach with a low operative mortality, good palliation, and already promising results merits close attention. At this stage a controlled clinical trial of surgery with and without preoperative irradiation may come within the narrow limits imposed by ethical considerations.-I am, etc.,

$$
\begin{aligned}
& \text { Glasgow Institute for } \\
& \text { Radiotherapy, } \\
& \text { Belvidere Hospital, } \\
& \text { Glasgow. } \\
& \text { REPERENCB } \\
& \text { Nakayama, K., Orihata, H., and Yamaguchi, K., } \\
& \text { Cancer (Philad.), 1967, 20,778. }
\end{aligned}
$$

